\title{
ANÁLISE DE UM PROJETO DE EFICIÊNCIA ENERGÉTICA EM UM POSTO DE COMBUSTÍVEIS COM BASE METODOLÓGICA NO PROTOCOLO INTERNACIONAL DE MEDIÇÃO E VERIFICAÇÃO DE PERFORMANCE (PIMVP)
}

\author{
Airton de Souza Gama Neto \\ Engenheiro de Produção /ISECENSA \\ airtoneto@hotmail.com \\ Lúcio Fabiano Sales Garcia \\ Engenheiro de Produção/ ISECENSA \\ 1fsgarcia@gmail.com \\ William Alves de Souza Gomes \\ Engenheiro de Produção/ ISECENSA \\ william_alves07@yahoo.com.br \\ Anderson Prado Azevedo \\ MSc. em Engenharia Elétrica/ UFES - Universidade Federal do Espirito Santo \\ anderpaz@yahoo.com.br
}

\section{RESUMO}

Nos dias atuais, as empresas estão buscando cada vez mais soluções para melhorar a eficiência do sistema de energia, porém, os grandes desafios deste setor estão no aumento do custo e da demanda, além da integração de fontes renováveis e do envelhecimento da infraestrutura energética. A utilização racional de energia, chamada simplesmente de eficiência energética, consiste em usar menos energia para fornecer a mesma quantidade de valor energético. Por sua vez, eficiência energética é uma atividade que procura aperfeiçoar o uso das fontes de energia. Este trabalho visa analisar a eficiência energética com a aplicação de metodologias propostas no protocolo de medição e verificação. Este protocolo permite conhecer o quanto está sendo efetivamente economizado, de modo a otimizar o consumo e gastos de energia, a fim de aumentar a produtividade; visando uma boa gestão em eficiência energética. Com base neste Protocolo Internacional de Medição e Verificação de Performance (PIMVP) foi desenvolvido um estudo de caso para avaliar a implantação da eficiência energética em um Posto de Combustíveis, no município de Campos dos Goytacazes - Rio de Janeiro, assim como uma elaboração do diagnóstico energético das instalações do posto de combustíveis, onde foram feitos levantamentos de dados em campo e medições do consumo de energia, com o intuito de verificar a viabilidade econômica e a redução do consumo e gastos de energia elétrica.

Palavras-chave: Eficiência Energética - Medição \& Verificação; Gestão em Eficiência Energética.

\footnotetext{
ABSTRACT

Nowadays, companies are increasingly seeking solutions to improve the efficiency of energy, however, major challenges is this sector are rising cost and demand, and integration of renewable sources and an aging energy infrastructure. The rational use of energy, simply called energy efficiency is to use less energy to provide the same amount of energy value. In turn, energy efficiency is one activity that seeks to improve the use of energy sources. This work 
aims to analyze the energy efficiency with the application of methods proposed in the protocol of measurement and verification. This protocol allows to know hows much is actually being saved, in order to optimize energy comsumption and expenditure in order increase productivity seeking a sound energy efficiency. Based on this Protocol International Performance Measurement and Verification (IPMVP) was developed a case study to evaluate the implementation of energy efficiency in a gas station in the municipality of Campos dos Goytacazes - Rio de Janeiro, as well as elaboration of diagnosis energy of the gas station facilities where surveys were made of field data and measurements of energy consumption, in order to determine the economic viability and reduction of consumption and spending power.

Keywords: Energy Efficiency - Measurement \& Verification; Management in Energy Efficiency.

\section{INTRODUÇÃO}

Eficiência energética é aperfeiçoar o uso de energia com o objetivo de produzir a mesma capacidade de trabalho num equipamento não eficiente. Desta forma, com ela visa-se aperfeiçoar o uso das fontes de energia, gastando menos e produzindo a mesma quantidade de trabalho.

Para Pereira (2011, p.2), “[...] entende-se por "Eficiência energética" o rácio entre o resultado em termos de desempenho e dos serviços, bens ou energia gerados e a energia utilizada para o efeito, [...]".

A eficiência energética é uma atividade técnico-econômica que objetiva proporcionar o melhor consumo de energia com correspondente redução de custos operacionais. Com ela podese minimizar contingenciamentos no suprimento desses insumos, introduzindo elementos e instrumentos necessários para o gerenciamento energético da empresa ou empreendimento.

Segundo Sola, (2006, p.12) "Em sistemas de conversão de energia (KOSOV, 1986) o conceito de eficiência energética está ligado à minimização de perdas na conversão de energia primária em energia útil, que realiza trabalho.”

Hoje em dia, as empresas buscam cada vez mais investir em eficiência energética a fim de suprir os constantes desafios para redução de custos e desperdícios. Através do processo de Medição \& Verificação as empresas, além de economizar com os gastos da produção, reduzem as emissões dos gases do efeito estufa, gerando benefícios econômicos e ambientais.

Em função da crescente discussão mundial sobre eficiência energética, a Efficiency Valution Organization - EVO publicou o Protocolo Internacional de Medição e Verificação de Performance - PIMVP, para aumentar os investimentos na eficiência energética e consumo eficiente de água, gestão do consumo e projetos de energia renovável em todo o mundo.

De acordo com o Guia de Medição \& Verificação (2007, p.12), o Protocolo Internacional de Medição e Verificação de Performance (PIMVP), teve o seu desenvolvimento iniciado por um grupo de voluntários reunidos por iniciativa do Departamento de Energia dos Estados Unidos (DOE - Departament of Energy) motivados pelos baixos investimentos em projetos de eficiência energética devido às incertezas relacionadas às economias futuras a serem obtidas por meio dessas ações. (GUIA DE MEDIÇÃO e VERIFICAÇÃO, 2007, p.12)

O PIMVP oferece diversas vantagens que trazem benefícios para as empresas que acarretam em economia e eficiência alcançada, porém não apresenta regras rígidas quanto ao tipo de eficiência energética. Algumas vantagens do PIMVP são: justificação dos Pagamentos 
para o desempenho energético, redução dos custos de transação num Contrato de Desempenho Energético, ajudar as organizações nacionais e industriais a promover e a obter o uso eficiente dos recursos.

Ainda segundo o Guia de Medição \& Verificação (2007, p.12):

\begin{abstract}
"Umas das grandes vantagens do Protocolo é exatamente o fato de não apresentar regras rígidas para cada tipo de ação de eficiência energética, pois, na prática, cada ação apresenta as suas características particulares e, caso a Medição \& Verificação fosse demasiadamente "engessada", sua implantação poderia ser inviável.” (GUIA DE MEDIÇÃO e VERIFICAÇÃO, 2007, p.12)
\end{abstract}

Segundo Haddad, et al. (2010, p.309).

"No ambiente altamente competitivo em que se encontram as empresas, a busca pelo uso racional de energia assume um caráter estratégico." Eliminar desperdícios, reduzir perdas e a racionalização técnico econômica na produção, tornaram-se elementos de grande importância.

O conforto e o bem-estar seriam praticamente impossíveis sem a energia elétrica, Haddad, et al. (2010) afirmam que:

\begin{abstract}
"A vida hoje seria praticamente impossível sem o conforto e o bem-estar proporcionado pela energia elétrica. A sua produção necessita cada vez mais de investimentos em infra-estrutura para a construção de novas unidades geradoras e linhas de transmissão, pois no Brasil, o consumo de energia elétrica vem aumentando a cada ano. Isso acontece porque o Brasil precisa crescer, mas parte é caracterizada pelo desperdício de energia". (HADDAD, et al., 2010, p.325)
\end{abstract}

De acordo com o PIMVP (2001, p.11), "quando as empresas investem em eficiência energética, seus executivos naturalmente desejam saber o quanto economizaram e quanto tempo as economias irão durar."

O PIMVP apresenta vários princípios que são aplicados a qualquer bom processo de Medição e Verificação, que visa à utilização de medidas para determinar de modo seguro a economia obtida. Algumas ações referentes ao Protocolo de Medição e Verificação necessitam de um planejamento pré-determinado dos procedimentos a serem adotados pelo projeto.

Ainda neste sentido o PIMVP (2001, p.11), diz que "a determinação das economias em energia requer medição precisa e metodologia reprodutível, conhecida como protocolo de medição e verificação."

De acordo com o PIMVP (2001, p.10), a eficiência energética oferece:

“[...] maior e melhor oportunidade de custo efetivo para os países industrializados e para os em desenvolvimento para limitar os enormes custos financeiros em saúde e meio-ambiente associados à queima de combustíveis fósseis. Os investimentos de custo efetivo disponíveis para eficiência nos usos de energia e água são globalmente estimados em dezenas de bilhões de dólares por ano. Entretanto, o nível atual de investimento é muito menor, representando apenas uma fração das oportunidades financeiramente atrativas existentes para investimentos em economias de energia." (PIMVP, 2001, p.10) 
Em um aspecto mais amplo, pode-se dizer que a eficiência energética é promover a utilização racional e consciente da energia combatendo o desperdício e contribuindo na ampliação da consciência da sociedade.

De acordo com Reis e Cunha (2006, p.19) "o aumento da eficiência do setor energético envolve atividades que vão desde a prospecção e utilização dos recursos naturais até a desmontagem dos projetos e o seu impacto ao meio ambiente."

Ainda neste sentido, o PIMVP (2001, p.17), definiu que "os projetos de uso eficiente de energia têm uma série de objetivos, como o da melhoria da qualidade do equipamento, melhoria do desempenho, ajuda para alcançar consenso ambiental ou simplesmente economizar energia e dinheiro."

A eficiência de energética é a uma solução econômica, eficaz e rápida, pois minimiza o uso de recursos naturais e custos da produção, além de melhorar o desempenho das empresas, tanto para inovação quanto para qualidade de serviços. Uma boa gestão em eficiência energética faz com que as empresas reduzam o consumo de energia, e contribuindo, portanto, para a redução do impacto das atividades sobre o clima, além de tornar as mesmas mais competitivas.

\section{PROBLEMÁTICA E HIPÓTESE}

Quando as empresas investem em eficiência energética, seus executivos naturalmente desejam saber o quanto economizaram e quanto tempo as economias irão durar. A determinação das economias em energia requer medição precisa e metodologia reprodutível, conhecida como protocolo de medição e verificação.

Uma solução para superar este problema é instituir uma consistente metodologia de medição e verificação de eficiência energética junto a um sistema de monitoramente confiável.

\section{OBJETIVOS}

\subsection{Objetivo geral}

Este trabalho tem por objetivo analisar, através do Protocolo de Medição e Verificação, a aplicação de recursos em projetos de eficiência energética, além de determinar as economias utilizando os dados disponíveis com qualidade adequada, num determinado Posto de Combustíveis, no Município de Campos dos Goytacazes - RJ.

\subsection{Objetivos específicos} específicos:

Com a elaboração deste trabalho, almeja-se demonstrar os seguintes objetivos 
a) Verificar o projeto de eficiência energética implantada em um posto de combustíveis;

b) Identificar as economias baseada no posto de combustíveis;

c) Analisar as economias obtidas pelo posto de combustíveis;

d) Analisar os resultados para verificar a viabilidade de implantação em outros postos de combustíveis, bem como em indústrias e projetos.

\section{MOTIVAÇÃO}

O uso eficiente da energia e dos recursos naturais é uma das mais importantes formas de efetivamente atingir a sustentabilidade. No Brasil, apesar de bastante divulgada pelo PROCEL, poucas empresas, executivos e profissionais do ramo aderiram ao protocolo e assim executam seus projetos sem o devido conhecimento de quanto está sendo economizado.

A $\mathrm{M} \& \mathrm{~V}$ é fundamental para a contabilização dos resultados obtidos em um projeto de economia de energia, visto que no Brasil ainda existe pouco interesse profissional na área, com isso vimos uma oportunidade de mostrar a importância deste assunto. Assim, visando implantar os processos do PIMVP, a empresa reduzirá seus custos e aumentará sua capacidade produtiva, além de melhor da qualidade dos produtos.

\section{METODOLOGIA}

\subsection{Classificação}

Este trabalho será classificado, de acordo com Silva e Menezes (2001), do ponto de vista da sua natureza como aplicada, pois objetiva a geração de conhecimentos para solucionar problemas específicos.

Em relação à forma de abordagem do problema, ele será classificado como quantitativa, porque demonstrarão através de números, valores dos resultados obtidos e transformados em dados.

No tocante aos objetivos, a pesquisa é classificada como descritiva, devido à coleta de dados onde assume forma de levantamento.

E por fim, do ponto de vista dos procedimentos técnicos: Estudo de caso, porque envolverá um estudo profundo e detalhado para realizar a análise dos resultados.

\subsection{Pesquisas metodológicas}

Em função da crescente discussão mundial sobre eficiência energética, a Efficiency Valution Organization - EVO publicou o Protocolo Internacional de Medição e Verificação de Performance - PIMVP, para aumentar os investimentos na eficiência energética e consumo eficiente de água, gestão do consumo e projetos de energia renovável em todo o mundo.

A Medição e Verificação $(\mathrm{M} \& \mathrm{~V})$ é uma metodologia empregada para comprovar os resultados de economia, em energia e custos, resultantes de ações de eficiência energética, sobretudo resultantes de trocas ou retrofits de equipamentos.

O Protocolo apresenta um consenso das melhores práticas para medição e verificação do desempenho da energia renovável, de modo a aumentar a confiança do investidor no desempenho de longo prazo dos sistemas de energia renovável. 
Além disso, o Protocolo fornece uma visão geral das melhores práticas atualmente disponíveis para verificar os resultados de projetos de eficiência energética, eficiência em água e de energia renovável. Ele também pode ser utilizado por operadores de instalações para avaliar e melhorar o desempenho delas.

A população a ser estudada será um posto de combustíveis, no Município de Campos dos Goytacazes, e as amostras serão obtidas através do banco de dados (através de pesquisas e resultados), e analisada para que se faça a gestão e para que se obtenha a eficiência energética.

\subsection{Procedimentos técnicos}

O Protocolo Internacional de Medição e Verificação apresenta quatro opções sobre como pode ser realizada a Medição e Verificação, sendo função do planejador/projetista determinar qual é a melhor empregada para o caso em questão. Os custos são diferentes para cada opção, pois envolve maior ou menor grau de medição, expertise ou recursos de informática.

\subsubsection{Opção A - Retrofit parcialmente isolado}

Nesta opção o protocolo define que "alguns parâmetros, mas não todos, podem ser estimados", ou seja, pelo menos um dos parâmetros de influência sobre o consumo deve ser medido, podendo os demais ser estimados ou estipulados.

As economias são determinadas através de cálculos de engenharia utilizando dados provenientes de estimativas e medições pós-retrofit. Um exemplo de aplicação típica é o retrofit de um sistema de iluminação, onde a potência instantânea é medida e as horas de funcionamento são estimadas.

\subsubsection{Opção B - Retrofit isolado}

Nesta opção todos os parâmetros de influência sobre o consumo devem ser medidos. As economias são determinadas através de cálculos de engenharia utilizando dados provenientes de medições curtas ou contínuas.

Um exemplo de aplicação típica é a utilização de variador de freqüência em uma bomba. Um medidor é colocado por um período pré-retrofit para determinar a baseline e continuará a medir o consumo de energia pós-retrofit por um determinado período.

\subsubsection{Opção C - Medição de toda a instalação}

As economias são determinadas diretamente a partir do medidor principal de energia da concessionária, com medições curtas ou contínuas durante o período de pós-retrofit.

A medição de toda a instalação reflete a origem do Protocolo, inicialmente desenvolvido para a Medição e Verificação em prédios públicos. Esta opção somente deve ser aplicada caso a economia esperada seja superior a $10 \%$ do consumo do ano base e dificilmente poderá ser aplicada em Medição e Verificação no setor industrial.

Uma aplicação típica ocorre na instalação de um sistema múltiplo de gerenciamento de energia em um edifício, onde diversos controles e retrofits interagem entre si. 


\subsubsection{Opção D - Simulação calibrada}

Por simulação calibrada entende-se um modelo matemático que reflete o consumo de uma instalação, ajustado (calibrado) em relação aos registros de energia disponíveis.

As economias são determinadas por meio de simulação do consumo de energia de alguns componentes ou de toda a instalação. Os modelos matemáticos devem refletir o consumo atual medido nas instalações e esta opção requer bastante conhecimento de simulações calibradas.

Uma aplicação típica ocorre na instalação de um sistema múltiplo de gerenciamento de energia em um edifício, do qual não se podem obter dados consistentes para geração de uma base. Neste caso, o consumo pós-retrofit é determinado através dos medidores da concessionária, por exemplo, o consumo do ano base (pré-retrofit) é calibrado com base nestes dados após a implementação das medidas.

\subsection{Análise dos resultados}

A análise dos resultados será feita através da classificação dos procedimentos técnicos, como pode ser visto na Tabela 1.

Tabela 1: Classificação dos procedimentos técnicos. Fonte: PIMVP, 2001, p.44.

\begin{tabular}{|c|c|}
\hline $\begin{array}{l}\text { OPÇÃO A - Retrofit } \\
\text { Parcialmente Isolado }\end{array}$ & $\begin{array}{l}\text { - Número de pontos de medição } \\
\text { - Complexidade da estipulação } \\
\text { - } \quad \text { Freqüência da inspeção pós-retrofit }\end{array}$ \\
\hline $\begin{array}{l}\text { OPÇÃO B - Retrofit } \\
\text { Isolado }\end{array}$ & - Número de pontos de medição \\
\hline $\begin{array}{l}\text { OPÇÃO C - Medição } \\
\text { de toda Instalação }\end{array}$ & $\begin{array}{l}\text { - Número de medidores } \\
\text { - Número de variáveis independentes necessárias para avaliar a } \\
\text { maioria da variabilidade nos dados de energia }\end{array}$ \\
\hline $\begin{array}{l}\text { OPÇÃO D - } \\
\text { Simulação Calibrada }\end{array}$ & $\begin{array}{l}\text { - Número e complexidade dos sistemas simulados } \\
\text { - Número de medições de campo necessárias para prover dados } \\
\text { de entrada } \\
\text { - Habilidade do profissional em simulação para alcançar a } \\
\text { calibragem }\end{array}$ \\
\hline
\end{tabular}

Persp. online: exatas \& eng., Campos dos Goytacazes, 2 (1), 54-73, 2011 


\subsection{Limitações}

As metodologias para coleta de dados diferem em grau de dificuldade e, conseqüentemente, no volume de dados errados ou faltantes. Nenhuma coleta consiste em ser realizado sem erros, por isso o plano de $\mathrm{M} \& \mathrm{~V}$ deve considerar dois aspectos dos problemas de coleta de dados:

1 - Estabelecer o número máximo aceitável de perda de dados e como serão medidos, este nível deve ser parte da consideração geral de precisão. O nível de perda de dados pode afetar drasticamente o custo.

2 - Estabelecer uma metodologia pela qual os dados faltantes ou errados sejam intercalados para análise final. Em tais casos, os modelos do ano-base e pós-retrofit podem ser usados para calcular as economias.

\section{BENEFICIOS DO PROTOCOLO DE MEDIÇÃO E VERIFICAÇÃO}

As mudanças de consumo de energia esperadas são detectadas com utilização de modelos matemáticos no desenvolvimento de um plano de medição e verificação, desde que as variáveis de influência tenham sido consideradas.

As medições aumentam a economia de energia pois permite aos gestores das empresas controlarem melhor o consumo de energia em suas instalações, permitindo-lhes ajustar a sua produção e maiores economias, por um período mais prolongado e com menores variações ao longo do tempo.

O emprego de Medição \& Verificação possibilita uma melhor engenharia de projeto de eficiência, levam naturalmente a um melhor projeto de retrofit, visto que há uma verificação dos resultados obtidos baseada em medição e não em estimativas.

Com a apresentação de um Plano de Medição \& Verificação consistente, boa parte do risco do projeto é minimizada. Sendo o risco um dos componentes do custo de qualquer projeto, esta minimização permite a redução da parcela referente ao mesmo, que pode ser bem elevada nos casos de uma inexistência de um plano.

Como na Medição \& Verificação ocorre primeiro a determinação da redução de energia consumida para somente depois calcular-se a economia pecuniária, é possível determinar a contribuição do projeto na redução de gases de efeito estufa.

\section{PROCEDIMENTOS DO PIMVP}

$\mathrm{O}$ protocolo de $\mathrm{M} \& \mathrm{~V}$ discute os procedimentos que, quando implementados, permitem aos compradores, vendedores e financiadores de projetos de energia e água concordarem com um plano de $\mathrm{M} \& \mathrm{~V}$ e quantificarem as economias provenientes das Ações para Conservação de Energia (ACE) e das Ações para Conservação de Água (ACA).

Assim como colocado, a finalidade do PIMVP é aumentar os investimentos em eficiência energética e energia renovável. Isto pode ser realizado pelo menos de seis maneiras:

a) Aumentar as economias em energia;

b) Reduzir o custo de financiamento dos projetos; 
c) Encorajar melhores projetos de engenharia uma vez que boas práticas de $M \& V$ estão intimamente ligadas a bons projetos de retrofits, os procedimentos do PIMVP;

d) Ajudar a demonstrar e apreender o valor das emissões reduzidas por meio de investimentos em eficiência energética e energia renovável;

e) Aumentar a compreensão sobre o gerenciamento de energia como uma ferramenta política pública através da melhoria da credibilidade dos projetos de gerenciamento de energia;

f) Auxiliar as organizações nacionais e industriais a promoverem e alcançarem eficiência nos recursos e objetivos ambientais.

Ao proporcionar economias maiores e mais confiáveis e uma abordagem comum para determinar as economias, a adoção deste Protocolo já tornou mais confiável e rentável, os investimentos em eficiência e favoreceu o desenvolvimento de novos tipos de redução do custo de financiamentos.

O PIMVP está sendo muito adotado por agências governamentais nacionais e regionais e por organizações industriais e comerciais para auxiliar no aumento de investimentos em eficiência energética e para alcançar benefícios ambientais e também na saúde.

\section{ESTUDO DE CASO}

Este estudo expõe a experiência de um posto de combustíveis localizado em Campos dos Goytacazes no Estado do Rio de Janeiro, que possui um sistema elétrico alimentado pela concessionária regional de eletricidade - AMPLA. O posto de combustíveis de derivados de petróleo tem como principal produto o GNV (Gás Natural Veicular) e atende ao mercado do município e cidades circunvizinhas. Além do posto em questão, a rede é composta por mais 03(três) estabelecimentos distribuídos pela cidade.

Os custos com energia elétrica têm significativa importância no balanço financeiro da empresa, justificando um melhor gerenciamento do uso desta energia, que visa à redução de custos e conseqüentemente o aumento dos lucros.

Este estudo tem por objetivo apresentar uma análise do projeto de eficiência energética já implementado pelo posto. Para tal, será utilizada a filosofia apresentada na opção $\mathrm{C}$ de medição e verificação do Protocolo Internacional de Medição e Verificação de Performance (PIMVP).

A opção $\mathrm{C}$ foi escolhida pelos seguintes motivos: a medição será realizada em toda a instalação a partir do medidor principal da concessionária; os dados extraídos das faturas de energia foram utilizados para determinar a economia, sendo apurados os consumos do primeiro ano de funcionamento regular após a execução do projeto e; a economia esperada a ser alcançada é superior a $10 \%$ do consumo do ano base.

A opção C, neste caso, também se mostra mais vantajosa devido ao seu baixo custo de análise, pois todos os dados são extraídos diretamente das faturas e do histórico de consumo do consumidor.

Conforme o PIMVP (2007) descreve, selecionar um opção do protocolo é uma decisão técnica na concepção do programa baseada no conjunto de condições de cada projeto. A Figura 1 descreve uma lógica comumente usada na seleção da melhor opção. 


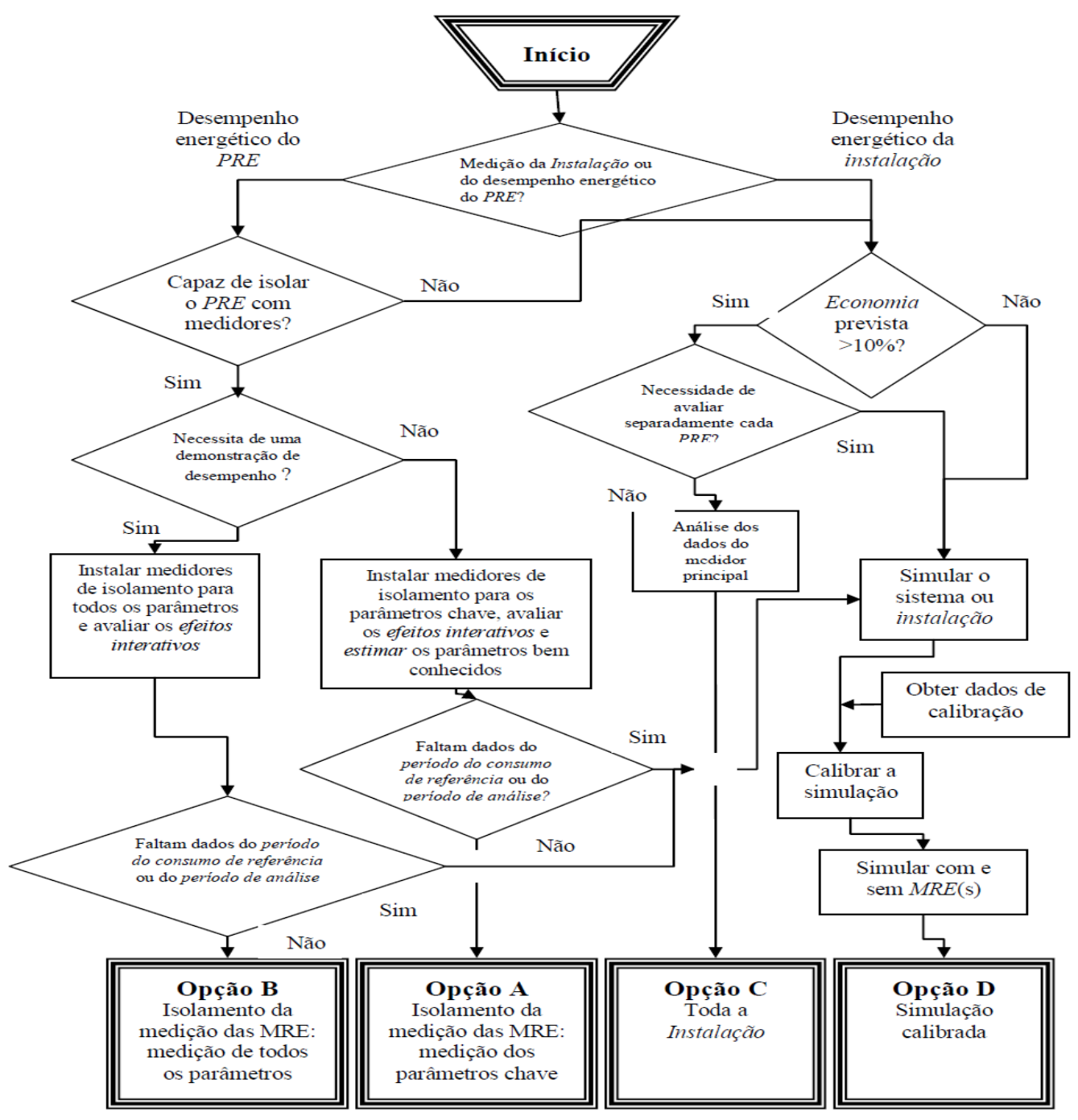

Figura 1: Processo de seleção da opção. Fonte: PIMVP (2007).

De acordo com o PIMVP (2007). "É impossível generalizar acerca da melhor opção de PIMVP para qualquer tipo de situação. No entanto, algumas características chave do projeto sugerem opções freqüentemente mais favorecidas". Veja exemplo na Figura 2. 


\begin{tabular}{|l|l|l|l|l|}
\hline \multicolumn{1}{|c|}{ Craterísticas da ARE do projeto } & \multicolumn{3}{|c|}{ Opção sugerida } \\
\cline { 2 - 5 } & A & B & C & D \\
\hline Necessidade de avaliar individualmente as AREs & $\mathrm{X}$ & $\mathrm{X}$ & & $\mathrm{X}$ \\
\hline $\begin{array}{l}\text { Necessidade de avaliar apenas o desempenho energético } \\
\text { de toda a instalação }\end{array}$ & & & $\mathrm{X}$ & $\mathrm{X}$ \\
\hline $\begin{array}{l}\text { Economia prevista inferior a 10\% do medidor da } \\
\text { concessionária }\end{array}$ & $\mathrm{X}$ & $\mathrm{X}$ & & $\mathrm{X}$ \\
\hline Múltiplas AREs & $\mathrm{X}$ & & $\mathrm{X}$ & $\mathrm{X}$ \\
\hline $\begin{array}{l}\text { A importância de algumas variáveis de energia não é } \\
\text { clara }\end{array}$ & & $\mathrm{X}$ & $\mathrm{X}$ & $\mathrm{X}$ \\
\hline $\begin{array}{l}\text { Os efeitos interativos da ARE são significativos ou não } \\
\text { podem ser medidos }\end{array}$ & & & $\mathrm{X}$ & $\mathrm{X}$ \\
\hline $\begin{array}{l}\text { Muitas alterações futuras previstas dentro do limite de } \\
\text { medição }\end{array}$ & $\mathrm{X}$ & & & $\mathrm{X}$ \\
\hline $\begin{array}{l}\text { É necessária uma avaliação do desempenho energético a } \\
\text { longo prazo }\end{array}$ & $\mathrm{X}$ & & $\mathrm{X}$ & \\
\hline Dados do período de referência indisponíveis & & & & $\mathrm{X}$ \\
\hline $\begin{array}{l}\text { Pessoal sem formação técnica devem compreender os } \\
\text { relatórios }\end{array}$ & $\mathrm{X}$ & $\mathrm{X}$ & $\mathrm{X}$ & \\
\hline Competência de medição disponíveis & $\mathrm{X}$ & $\mathrm{X}$ & & \\
\hline Competências de simulação por computador disponíveis & & & & $\mathrm{X}$ \\
\hline $\begin{array}{l}\text { Experiência de leitura das faturas de energia de empresas } \\
\text { comercializadoras de energia e realização de análise de } \\
\text { regressão disponíveis }\end{array}$ & & & $\mathrm{X}$ & \\
\hline
\end{tabular}

Figura 2: Opções sugeridas. Fonte: PIMVP (2007).

\subsection{Diagnóstico energético}

De acordo com Haddad, et al.(2010), "diagnóstico energético é uma metodologia aplicada em unidades comerciais e industriais, para o levantamento do perfil de consumo por uso final." Para tal, devem ser realizados levantamentos de dados em campo. Os dados obtidos são analisados permitindo a identificação qualitativa dos pontos críticos e a indicação das necessidades de atuação em sistemas e/ou equipamentos visando alcançar e otimizar o fornecimento de energia.

Para a elaboração do diagnóstico energético das instalações do posto em questão foram feitos levantamentos de dados em campo e medições do consumo de energia. Estas atividades foram realizadas em dezembro de 2008 da seguinte forma:

a) Levantamento das características das instalações elétricas e de iluminação existentes; 
b) Levantamento da demanda energética atual;

c) Realização de medição antes da implementação das medidas de eficiência energética;

d) Avaliação das instalações civis, com vistas à análise de possíveis adequações que possam tornar a edificação mais eficiente e;

e) Avaliação da necessidade de revisão do contrato de suprimento de energia elétrica em função do levantamento da demanda energética atual.

\subsection{Metodologia aplicada}

A metodologia aplicada neste projeto contou com levantamentos in loco e teve por objetivo atingir o máximo grau de confiabilidade dos dados a serem processados. Para isso as seguintes etapas foram desenvolvidas:

a) Visita técnica para conhecimento geral do funcionamento das instalações;

b) Levantamento do histórico das últimas 12 contas de energia elétrica da unidade consumidora;

c) Levantamento da documentação técnica e de dados referentes às instalações existentes (diagrama unifilar, planta baixa, especificações de equipamentos, etc.);

d) Entrevistas com pessoal de operação e manutenção visando conhecer aspectos operacionais e hábitos de uso dos equipamentos;

e) Análise dos diversos dados históricos de consumo;

f) Levantamento de todos os equipamentos instalados e seu ciclo de funcionamento (motores, bombas, sistemas de iluminação, de ar condicionado, de refrigeração e outros usos de energia significativos);

g) Identificação de equipamentos prioritários para a execução de ações e medidas para aumento da eficiência energética e;

h) Execução de medições de grandezas elétricas.

\subsection{Análise de dados}

Tendo sido construído em 2005, o posto apresenta uma estrutura moderna e instalações elétricas dentro dos padrões vigentes. Os dados históricos de consumo mostraram um consumo atípico no mês de janeiro de 2008, e por isso este mês foi descartado da análise. Os documentos referentes às instalações elétricas foram utilizados para uma identificação global do sistema, o que auxiliou mais tarde na instalação do grupo gerador. As entrevistas com os funcionários demonstraram que a rotina operacional segue aos padrões e em nada poderia ser modificada, já que o funcionamento dos equipamentos fica condicionado ao atendimento ao cliente. $\mathrm{O}$ levantamento dos equipamentos instalados mostrou que os mesmos estão dentro de especificação, destacando apenas que alguns motores estão passíveis de substituição por modelos de maior rendimento.

Com base no levantamento das cargas foi possível construir o gráfico da Figura 3, onde o motor do compressor representa $95 \%$ da carga total do posto, o sistema de iluminação $1 \%$, motores das bombas de combustíveis $2 \%$ e outros $2 \%$. Outros equipamentos são compostos por ar-condicionado, tv's, freezer, estufas, rádios, etc. 


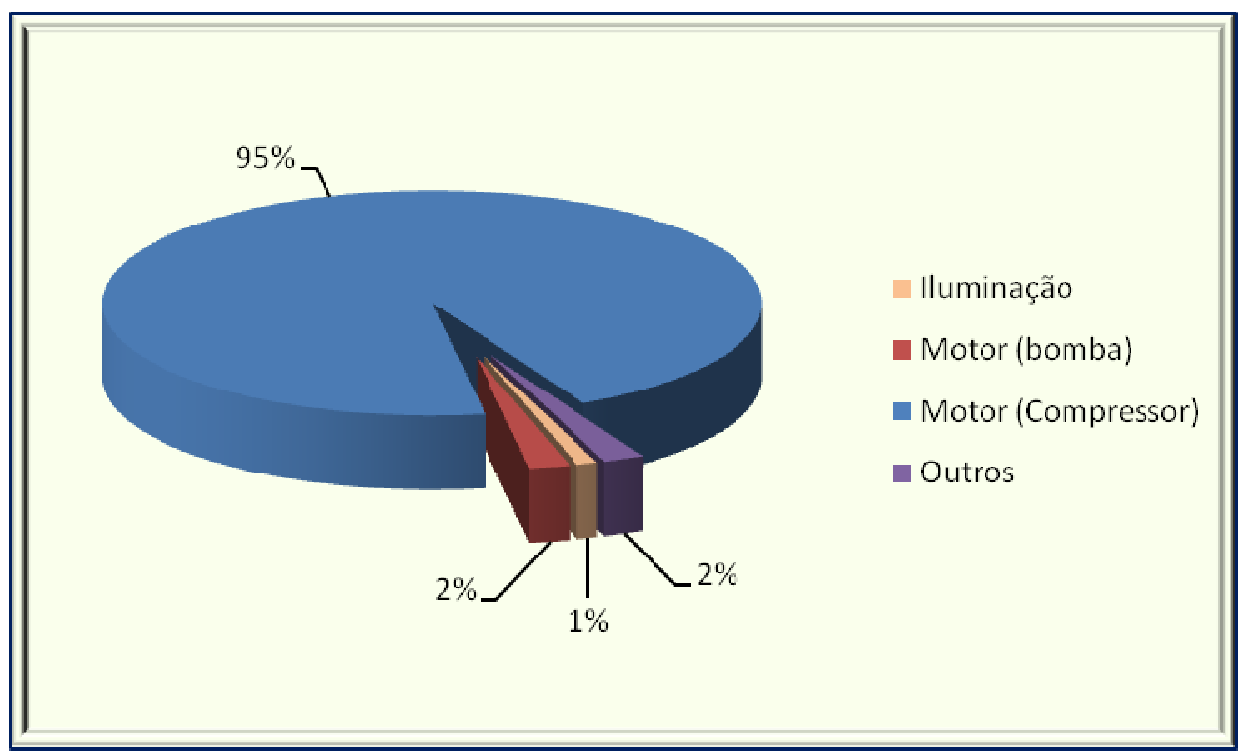

Figura 3: Levantamento de carga do posto. Fonte: Elaboração própria.

Analisando-se o gráfico apresentado acima é fácil perceber que a contribuição do motor de $200 \mathrm{CV}$, componente do conjunto de compressão de GNV, é extremamente considerável para o consumo total de energia do posto. Na Figura 4 observa-se um sistema completo de compressão de GNV, composto principalmente de um compressor alternativo de dois pistões e um motor elétrico de $200 \mathrm{cv}$.

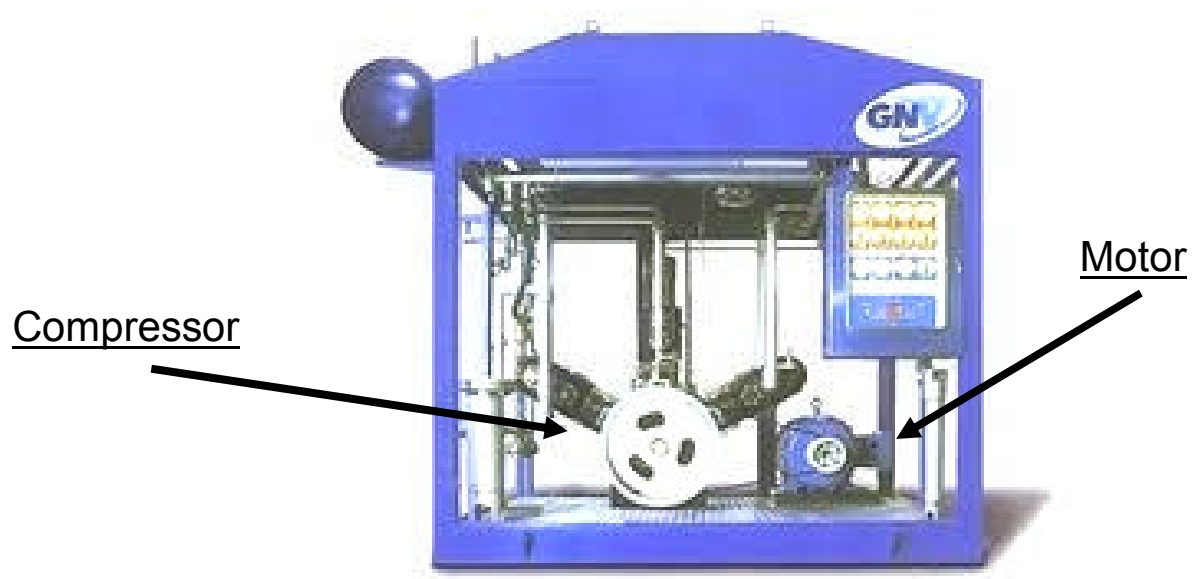

Figura 4: Compressor de GNV. Fonte: TELEMED.

O consumo médio mensal do posto, no período de março de 2008 a fevereiro de 2009, foi de $40.915 \mathrm{kWh}$. A Figura 5 apresenta o histórico de consumo e a média mensal do período. 


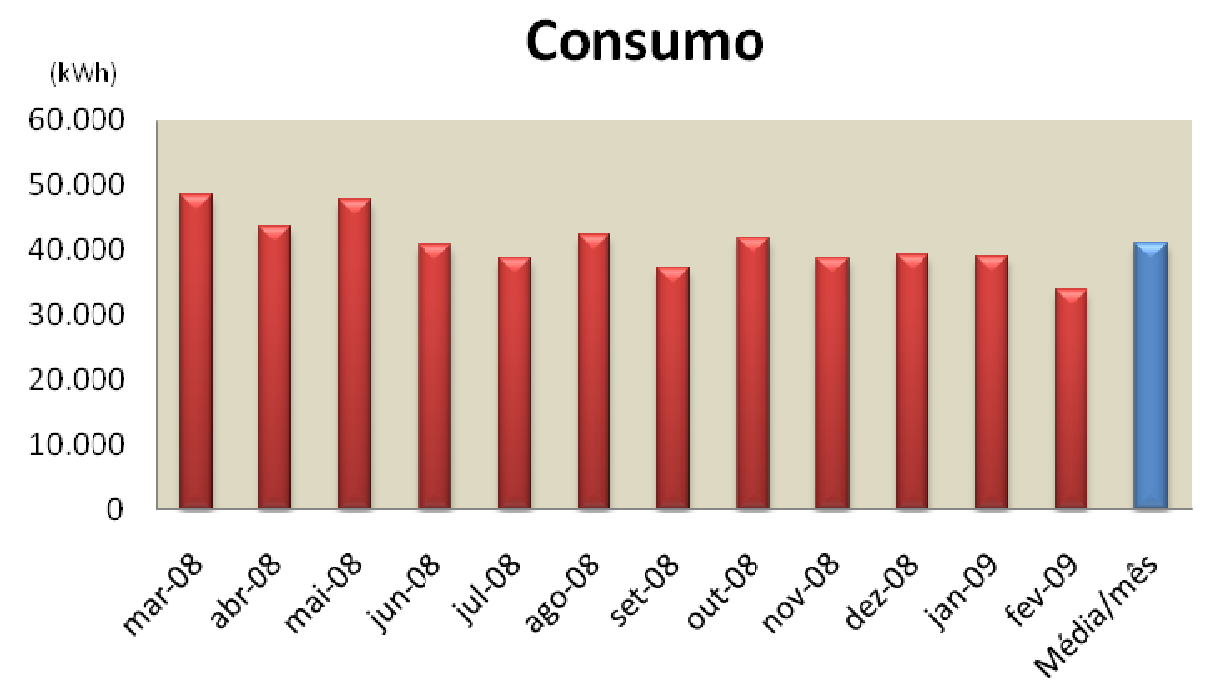

Figura 5: Histórico de consumo. Fonte: Elaboração própria.

Verifica-se no gráfico que não é possível a identificação de uma tendência sazonal por período. Ou seja, verão, inverno, férias, entre outros, não influenciam no consumo anual.

A Figura 6 apresenta o histórico de dispêndio com energia elétrica da instalação. $O$ período analisado foi o mesmo utilizado na análise de consumo mostrada acima. Esta análise de faturamentos serviu de base para o comparativo pós-retrofit. A média mensal da fatura de energia é de $\mathrm{R} \$ 11.005,91$.

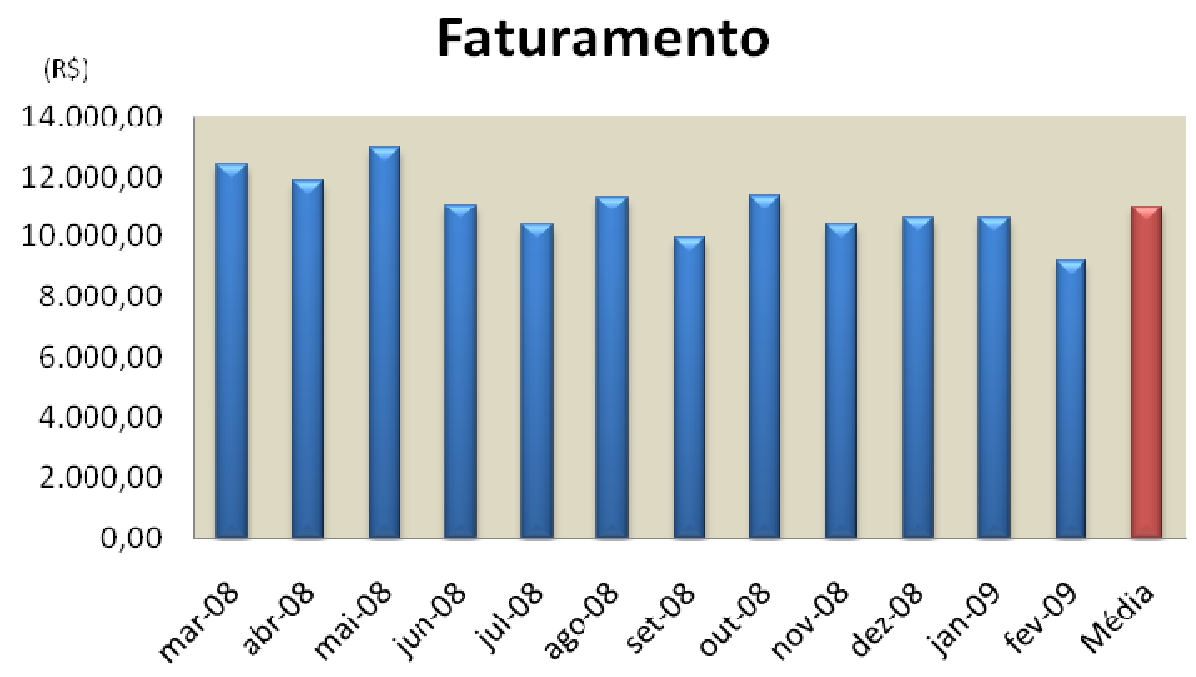

Figura 6: Histórico de Faturamento - valores em R\$ Fonte: Elaboração própria. 


\subsection{Situação anterior a implementação}

Com o fornecimento de energia elétrica exclusivamente provido da concessionária $\mathrm{o}$ posto contava com uma subestação com transformação de 13,8/0,22-0,44 kV, para uma potência instalada de $300 \mathrm{kVA}$. Este nível de tensão é necessário para alimentação do motor do compressor de GVN.

O consumo de energia do motor do compressor de GNV, por ser muito superior à soma dos consumos dos outros sistemas, fez este equipamento tornar-se um ponto principal a ser considerado no projeto de eficiência. Entende-se por outros sistemas a iluminação, demais motores elétricos, ar-condicionado e outros equipamentos. Estes não apresentaram vantagem econômica que justificasse a implementação de alguma medida voltada a eficiência energética.

Uma importante análise a ser considerada é do dispêndio financeiro que o consumidor tem com o uso de energia elétrica. O contrato de fornecimento era na modalidade Convencional Grupo A4, ou seja, são contratados um valor de demanda, expresso em $\mathrm{kW}$, para qualquer hora do dia ou mês e um valor único de consumo, expresso em $\mathrm{kWh}$.

\subsection{Principais medidas adotadas}

O posto possuía uma subestação simplificada com medição única em alta tensão onde as cargas eram atendidas por um único transformador e um contrato de fornecimento de energia elétrica na modalidade grupo A4 convencional, que é caracterizada pela aplicação de tarifas de consumo de energia elétrica e demanda de potência, independentemente das horas de utilização do dia e dos períodos do ano.

A melhor solução encontrada para a instalação contemplou a aquisição de um grupo gerador, o que possibilitou a alteração da modalidade tarifaria do contrato de fornecimento de energia elétrica junto com a concessionária alem de garantir uma maior confiabilidade e continuidade no atendimento a seus clientes.

A nova modalidade tarifaria foi determinada levando em consideração suas características, sendo a mais indicada a THS-Verde (Tarifa Horosazonal Verde) que caracterizase pela aplicação de tarifas diferenciadas de consumo de energia elétrica, de acordo com as horas de utilização do dia e os períodos do ano, assim como de uma única tarifa de demanda de potência.

Sendo assim, o grupo gerador, que é composto de uma unidade de $380 \mathrm{kVA}$, entra em funcionamento diariamente no horário de ponta, período composto por 3 (três) horas diárias consecutivas definidas pela distribuidora considerando a curva de carga de seu sistema elétrico, exceto sábados, domingos e feriados nacionais.

Também foi avaliada a corrente de partida dos motores, sendo considerado neste caso apenas a corrente do motor do sistema de compressão de GNV. Tal avaliação se faz necessária para o correto dimensionamento do grupo gerador.

$\mathrm{Na}$ avaliação foi identificado que o sistema inteligente de partida do motor estava fora dos parâmetros e conseqüentemente a corrente de partida estava alta. Foi então necessária o ajuste dos parâmetros de partida para que o grupo gerador dimensionado pudesse atender as necessidades do posto. posto.

A Figura 7 ilustra um grupo gerador similar ao analisado e posteriormente utilizado pelo 


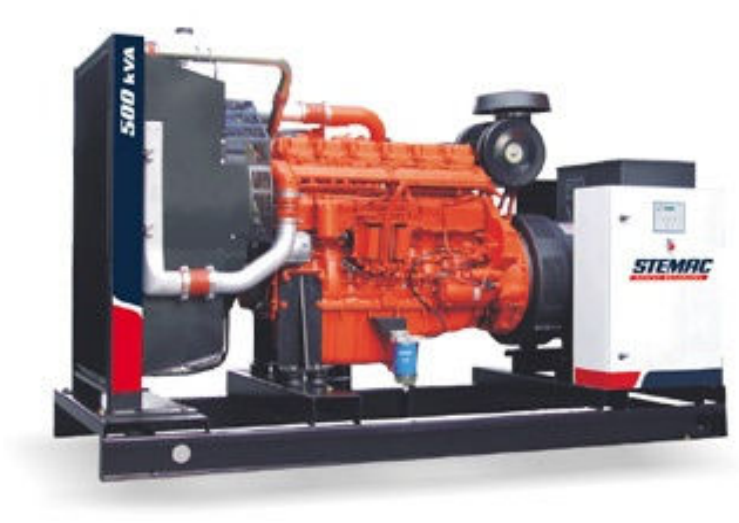

Figura 7: Grupo Gerador. Fonte: STEMAC.

A última etapa implantada pelo projeto de eficiência energética caracteriza-se por treinamento dos responsáveis pela operação do grupo gerador, além de divulgação da importância da correta aplicação do procedimento operacional proposto.

O investimento total para a aquisição e instalação do grupo gerador, considerando o fornecimento de todos os materiais e mão-de-obra foi de $\mathrm{R} \$ 160.000,00$. Como dito anteriormente os demais equipamentos não foram alterados ou substituídos.

O retorno do investimento foi estimado para 36 meses levando-se em conta a diferença entre o valor da fatura de energia elétrica antes e depois da implementação do projeto de eficiência energética. Vale ressaltar que esta estimativa considerou os custos com o combustível consumido pelo grupo gerador.

\subsection{Resultados obtidos}

Com a implantação do sistema de fornecimento alternativo de energia elétrica, constatou-se uma redução no consumo médio mensal de $16.615 \mathrm{kWh}$ e no consumo total anual de $199.375 \mathrm{kWh}$, fazendo-se um comparativo entre os anos de 2008 e 2010 e uma economia de R\$ 70.879,51/ano considerando a fatura cheia, conforme valores expressos no historio de faturamento das contas de energia elétrica do posto,. Nas figuras 8 e 9 verifica-se o comparativo de consumo de energia elétrica nos anos de 2008 a 2010. 


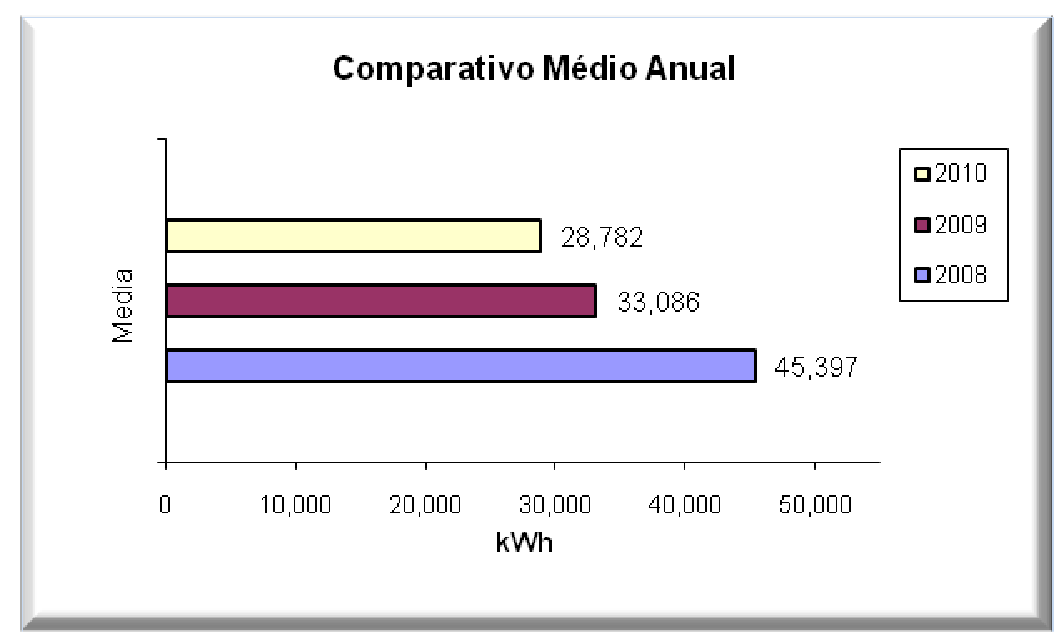

Figura 8: Histórico de consumo médio de energia elétrica do posto anos 2008, 2009 e 2010. Fonte: Elaboração própria.

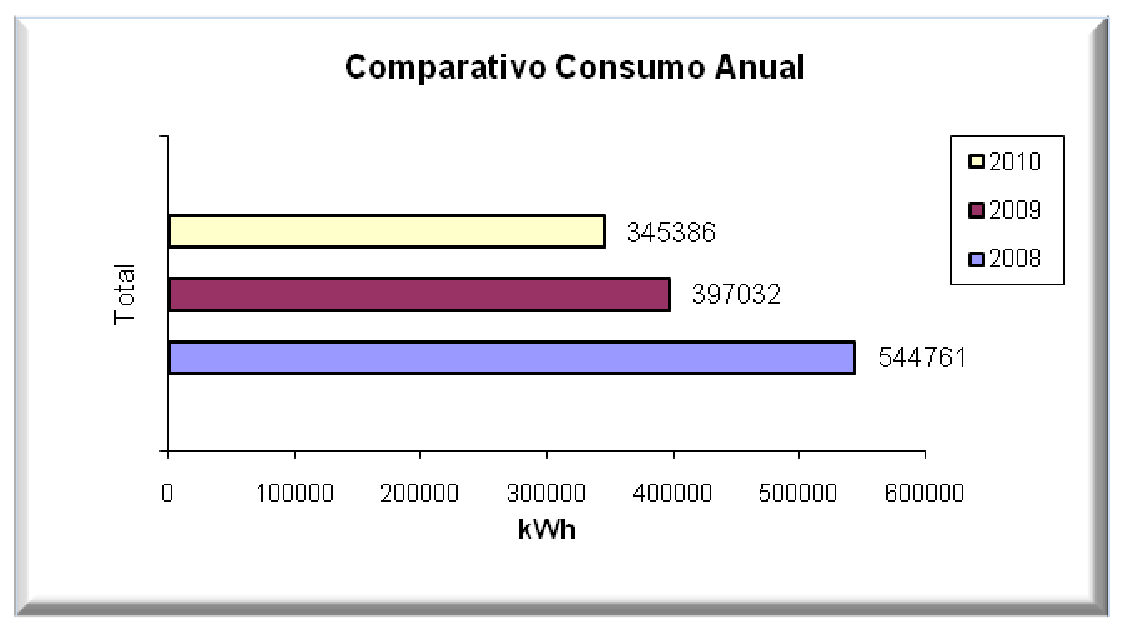

Figura 9: Histórico de consumo TOTAL de energia elétrica do posto nos anos de 2008, 2009 e 2010. Fonte: Elaboração própria.

\subsection{Conclusão}

A aplicação do protocolo nesta análise mostrou-se bem satisfatória, pode-se observar que a padronização da proposta para o diagnostico energético, metodologia aplicada e analise com base na opção $\mathrm{C}$ se mostraram úteis para o processo de coleta e analise dos dados.

A eficiência energética esperada foi alcançada levando-se em consideração a diminuição de quase a totalidade da demanda de energia antes utilizada no horário de pico. As principais medidas adotadas, que atualmente consiste em trabalhar com o grupo gerador neste horário e a parametrização do sistema de partida contribuíram diretamente para a redução da curva de carga no sistema de energia da região. 
Tal qual o horário de verão que tem como objetivo a redução da demanda máxima no sistema energético no horário de ponta, a utilização do grupo gerador também traz benefícios semelhantes porem para o ano todo. Veja na Figura 10 um exemplo de curva de carga e como a mesma se comporta ao longo do dia.

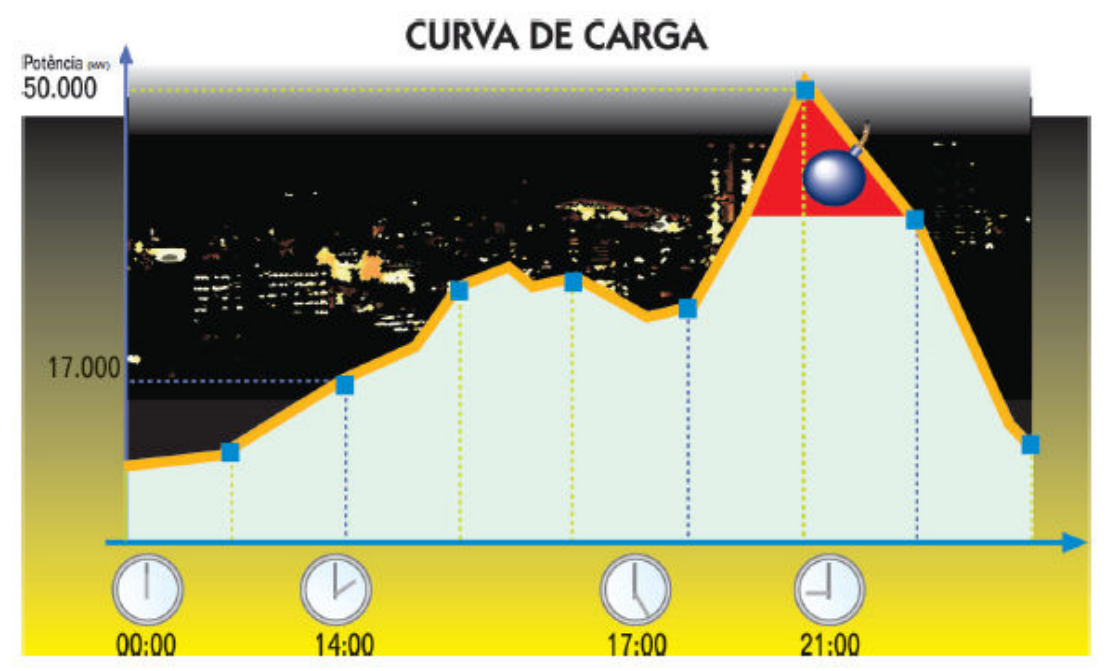

Figura 10: Exemplo de curva de carga brasileira. Fonte: Procel nas Escolas - livro 5.

A parametrização do sistema de partida trouxe benefícios de eficiência energética. Estas não puderam ser quantificados, pois este ajuste independe da utilização do grupo gerador e seria algo que poderia ter sido revisado a mais tempo. Veja na Figura 11 o comparativo entre métodos de partida:

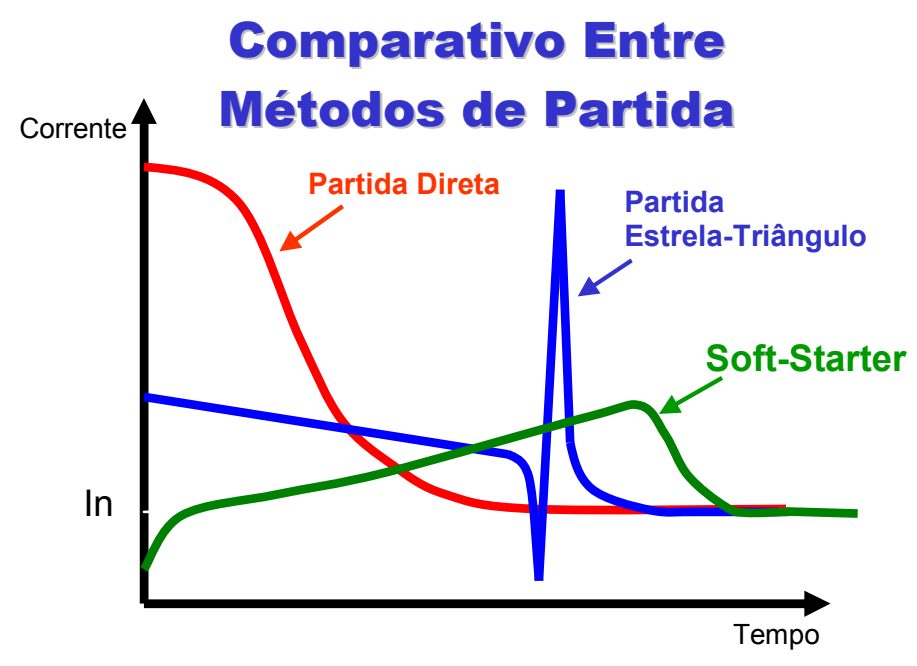

Figura 11: Sistemas de partida de motores. Fonte: WEG. 
Por outro lado, numa análise mais abrangente, verifica-se que houve apenas uma troca de fonte primaria de energia, que nesta situação um dos principais objetivos da eficiência energética não foi alcançado, a redução de emissão e geração de GEE.

Como o objetivo do estudo era verificar através do PIMVP a real eficiência energética conquistada, podemos então concluir que para este tipo de caso o protocolo atendeu as expectativas e mostrou os ganhos efetivamente conquistados.

\section{CONSIDERAÇÕES FINAIS}

A eficiência energética está se tornando uma meta cada vez mais imprescindível para as empresas e empreendimentos, visto que incentiva as mesmas aperfeiçoar o uso racional das fontes de energia utilizando menos e produzindo a mesma quantidade de trabalho. Dessa forma, a eficiência energética objetiva proporcionar o melhor consumo de energia evitando $o$ desperdício e a degradação ao meio ambiente.

Através da utilização do Protocolo de Medição e Verificação, as empresas podem obter ganhos nas áreas ambientais, produtiva e econômica. Em relação à eficiência ambiental, os ganhos são: a redução na emissão de $\mathrm{CO}_{2}$ e outros gases nocivos à saúde, menor incidência de doenças e como conseqüência faltas de funcionários, redução de desmatamentos, melhoria nas condições do ambiente de trabalho e a redução da produção de resíduos líquidos e/ou sólidos.

Com relação à eficiência produtiva, os ganhos são: aumento da capacidade produtiva, redução das despesas diretas referentes ao consumo ineficiente de energia, melhoria da qualidade dos produtos, economia das fontes de energia e dos processos dos empregados, além da melhoria no processo de produção.

E por fim, em relação à eficiência econômica, os ganhos alcançados são: aumento da lucratividade e financeiros, redução dos custos com energéticos, diminuição no prazo para amortização dos investimentos, menor investimentos em usinas hidrelétricas e termelétricas, contribuindo assim para o menor endividamento. Além do ganho na competitividade e atração de novos investimentos, aumentando assim a geração de empregos e renda.

\section{REFERÊNCIAS BIBLIOGRÁFICAS}

FREIRE, Ian Felisberto - Medição e Verificação em Eficiência Energética-Metodologia para Determinação do Baseline. 2001, 120p. Dissertação (Mestrado) - Curso de Pós Graduação em Engenharia Civil, Universidade Federal de Santa Catarina, Santa Catarina, 2001.

Guia de Medição e Verificação - Brasil, PROCEL/ELETROBRAS, 2007, p.12.

HADDAD, J. et al. Estudo de racionalização do consumo de energia elétrica em sistemas de tratamento e abastecimento de água, In: Gomes, H. P. (Org), Sistemas de Saneamento Eficiência Energética - João Pessoa: Editora Universitária/UFPB, 2010, p.309 - 316

HADDAD, J. et al. Caso prático de eficiência energética em uma edificação pública: projeto, implementação e análise do resultado, In: Gomes, H. P. (Org), Sistemas de Saneamento Eficiência Energética - João Pessoa: Editora Universitária/UFPB, 2010, p.325 - 331 
LEITE, F. C. Modelamento da eficiência energética para o gerenciamento no setor industrial pela medição e verificação. 2010. 94p. Dissertação (Mestrado) - Escola Politécnica, Universidade de São Paulo, São Paulo, 2010.

PEREIRA, N. B. R. de C. EFICIÊNCIA ENERGÉTICA NO SECTOR DOS TRANSPORTES RODOVIÁRIOS: METODOLOGIA PARA QUANTIFICAÇÃO DO EXCESSO DE ENERGIA CONSUMIDA DEVIDO AO FACTOR COMPORTAMENTAL NA CONDUÇÃO DE VEÍCULOS AUTOMÓVEIS LIGEIROS. 2011. 72p. Dissertação (Mestrado) - Faculdade de Ciências e Tecnologia da Universidade Nova de Lisboa, Lisboa, 2011.

Protocolo Internacional para Medição e Verificação de Performance - Brasil, Rio de Janeiro, INEE, Outubro, 2001, p.11.

REIS, L \& CUNHA, E. - Energia Elétrica e Sustentabilidade: Aspectos tecnológicos, socioambientais e legais - CIDADE: Editora Manole, 2006, 244p.

SILVA, E. L. \& MENEZES, E. M. - Metodologia da pesquisa e elaboração de dissertação, $3^{\text {a }}$ Ed. revisada e atualizada, 2001, 121p. - Laboratório de Ensino a Distância da UFSC, Florianópolis, 2001.

SOLA, A. V. H. \& KOVALESKI, J. L. Eficiência energética nas indústrias: cenários \& oportunidades. 2004. ENEGEP 2004 ABEPRO 3326. 8p.

STEMAC - Grupo Geradores. Disponível em: $<$ http://www.stemac.com.br/grupos-geradoresdiesel.html>. Acesso em: 25/Junho/2011.

TELEMED. Ambiental. Disponível em:

$<$ http://www.telemed.com.br/> Acesso em: 26/Junho/2011. 